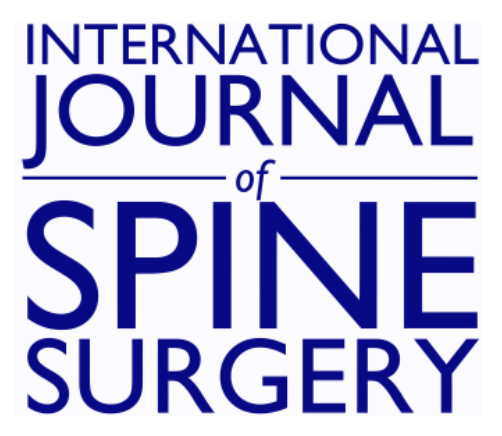

\title{
Long-Term Experience With Reduction Technique in High-Grade Spondylolisthesis in the Young
}

\author{
PRAMOD K SUDARSHAN, HARDIK R SUTHAR, VAMSI K VARMA, APPAJI KRISHNAN \\ and SAJAN K HEGDE
}

Int J Spine Surg 2018, 12 (3) 399-407

doi: https://doi.org/10.14444/5047

http://ijssurgery.com/content/12/3/399

This information is current as of April 26, 2023.

Email Alerts Receive free email-alerts when new articles cite this article. Sign up at:

http://ijssurgery.com/alerts 


\title{
Long-Term Experience With Reduction Technique in High-Grade Spondylolisthesis in the Young
}

\author{
PRAMOD K SUDARSHAN, MS ORTHO, ${ }^{1}$ HARDIK R SUTHAR, MS ORTHO, ${ }^{1}$ VAMSI K VARMA, MS \\ ORTHO ${ }^{1}$ APPAJI KRISHNAN, MS ORTHO ${ }^{2}$ SAJAN K HEGDE, MS ORTHO ${ }^{1}$ \\ ${ }^{I}$ Apollo Hospitals, Chennai, India, ${ }^{2}$ SIMS Hospitals, Chennai, India
}

\begin{abstract}
Background: Surgical management of high-grade spondylolisthesis in the young is not only challenging but also controversial, from in-situ fusion to complete reduction. It is fraught with dangers such as neurological injury, pseudoarthrosis, and progressive deformity with subsequent global sagittal imbalance. We describe our experience of progressive reduction technique and restoration of lumbosacral alignment.

Methods: This study is a retrospective review of patients who underwent surgery between 1998 and 2012. The surgical technique involved positioning the hips in extension with traction, pedicle screw fixation, correction of lumbosacral kyphosis with a specific distraction maneuver, wide decompression, and gradual reduction of the deformity and maintenance of reduction with interbody fusion. All patients were serially assessed at 1, 3, and 6 months and yearly thereafter with clinical, radiological, and Oswestry Disability Index and Visual Analogue Scale outcome measures.

Results: Twenty-seven patients with high-grade spondylolisthesis at L5-S1 (3 cases grade 3, 7 grade 4, 17 grade 5) with an average age of 13.9 years were reviewed. Mean follow-up was 120 months (range 24-192). All patients presented a solid fusion at the 6-month visit; mean slip percentage was reduced from $89 \%$ to $23 \%$, with all cases reduced to grade 2 or less. The slip angle improved from $45^{\circ}$ to $3^{\circ}$ postoperatively, with improvement in sacral slope from $13^{\circ}$ to $35^{\circ}$. Four spondyloptosis patients had concomitant scoliosis which corrected spontaneously after the surgery and did not need further intervention. All but one patient $(96.2 \%)$ had good functional outcomes and returned to their full normal activities. One patient developed a deep infection necessitating implant removal, with eventual deformity progression leading to a poor outcome. Three patients $(11.1 \%)$ suffered partial drop foot that resolved in full by 12 weeks.

Conclusion: Our technique demonstrated a significant reduction of high grade spondylolisthesis, with restoration of global sagittal balance via correction of the lumbosacral kyphosis. Though surgically demanding, it is safe and reproducible.
\end{abstract}

Level of Evidence: IV

Lumbar Spine

Keywords: high-grade spondylolisthesis, reduction, instrumentation, sagittal balance, lumbosacral kyphosis

\section{INTRODUCTION}

A particular predisposition to spondylolysis at lumbosacral junction is seen among physically active adolescents, with nearly $50 \%$ of lower back pains rooted in these structural deformities and the significantly shorter vertebrae fatigue life in this age group. ${ }^{1}$ At these developmental stages, higher intervertebral disc elasticity and incomplete ossification of the neural arches allows for transmission of a greater proportion of intervertebral shear force to the inferior facets, which inevitably fracture upon repetitive rotational loading.

It is generally accepted to include cases with more than $50 \%$ displacement of one vertebra over the other (Meyerding types 3 and 4 and spondyloptosis) as high-grade spondylolisthesis. The choice of treatment highly depends on degree of slippage and/or deformity, neurological findings, and the age of the patient. Conservative treatments are less likely to blunt slip progression and postural deformity in patients with high-grade spondylolisthesis. However, surgical management of high-grade spondylolisthesis in the young, by the way of techniques ranging from in-situ fusion to complete reduction, is not only challenging but also controversial. It is fraught with risks, ${ }^{2}$ such as neurological injury, pseudarthrosis, adjacent disc degeneration, facet joint hypertrophy, and subsequent global sagittal imbalance arising from the kinematic impact of the fused on the unfused segments. ${ }^{3}$ Staged anterior and posterior approaches are more 

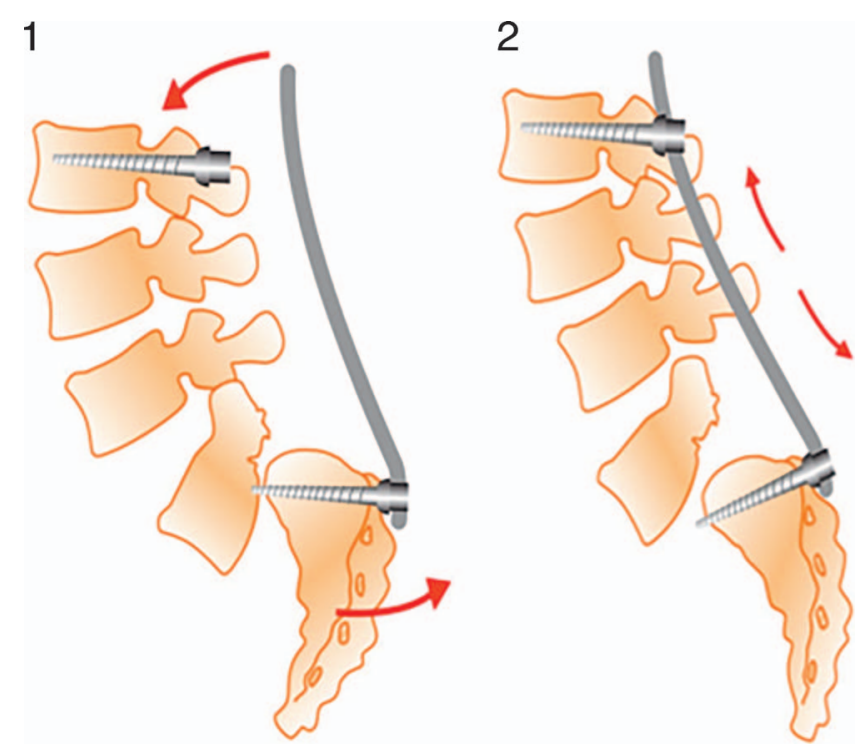

Figures 1 and 2. Correction of lumbosacral kyphosis is initiated by distraction using a cantilever mechanism between L2-3 screws and sacrum.

morbid and associated with a high rate of complications in young children.

With the common aim of fusing as few motion segments as possible, resolution of symptoms, and bringing to a near-normal restoration of the sagittal vertical axis of the lumbar spine, ${ }^{4}$ surgeons still debate over the ideal surgical technique, role of instrumentation, optimal alignment, and need for deformity reduction in high-grade spondylolisthesis. Incidence of neurological deficit is as high as $25 \%$ following staged posterior instrumentation, ${ }^{5}$ and has been significantly lowered, to $9 \%$, by introduction of pedicle screw fixation techniques. ${ }^{6}$ Slip angle reduction has been introduced to overcome these risks, by improving the sagittal lumbosacral orientation and providing for neural decompression, ${ }^{7}$ yielding normalization of the sagittal profile and load distribution. At the same time, it has been associated with a high rate of neurological complications. $^{8}$

We describe our long-term experience with a progressive, single-stage, posteriorly performed reduction technique for restoration of lumbosacral alignment and analyze the functional and radiological outcome.

\section{PATIENTS AND METHODS}

\section{Patients and Design}

A retrospective review of 27 consecutive pediatric and adolescent patients (aged 10-18 years) who underwent surgery using the progressive reduction

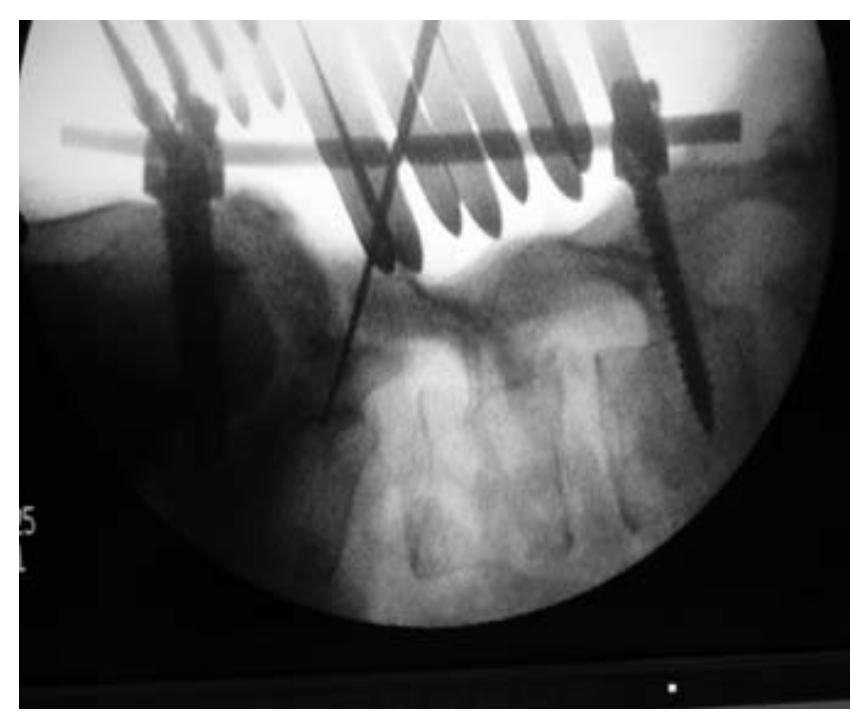

Figure 3. Distraction of the screws allows entry and insertion of pedicle screw into L5.

technique between 1998 and 2012 was performed. The hospital institutional review board approved the study.

Children with spondyloptosis especially presented with low back pain due to spasm and hamstring tightness. Widening of the ilial wings, flattened buttocks, thoracolumbar hyperlordosis leading to anteriorly protruding inferior ribcages, loss of trunk height leading to absent waist line and exaggerated flank creases with lumbar sag were the usual clinical findings. Limitation of straight leg rising was common but none of our patients presented with a motor deficit; however, 3 patients had sensory deficits at L5 at the time of presentation.

All patients were serially assessed at 1, 3, and 6 months and yearly postsurgery, by clinical examination including complete neurological status and analysis of symptoms, radiography, and grading of outcome measures Oswestry Disability Index (ODI) and visual analog scale (VAS).

Parameters to indicate fusion were clinical resolution of symptoms with a radiographically solid-appearing bone bridging anterior to the cages, consistency in maintenance of lumbosacral measurements, and no evidence of instrumentation failure, loss of reduction, or pseudarthrosis at 2 years.

\section{Surgical Technique}

The technique is a modified version of that described by Shufflebarger et $\mathrm{al}^{9}$ and Harms et al. ${ }^{10}$ 


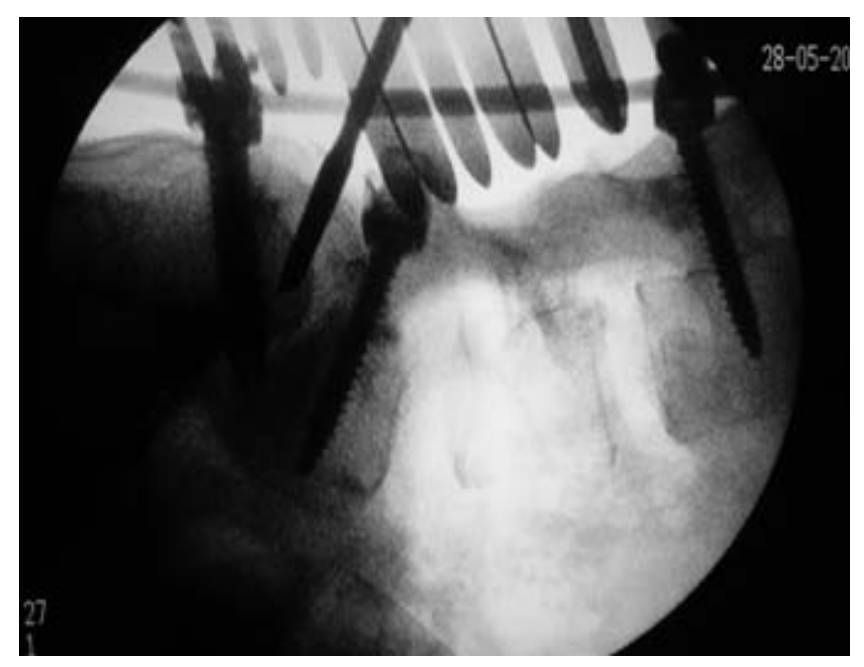

Figure 4. Sacral dome excision using an osteotome after L5 screw placement.

\section{Anesthesia and Positioning}

After induction with general endotracheal anesthesia, the patient was positioned prone on a Jackson frame with all pressure points well padded. The patient was positioned on the table with the hips at maximum extension to help the initial positional reduction. Accurate positioning has been described to help reverse the deformity. ${ }^{9}$ Intraoperative radiographs were obtained after positioning to check the amount of reduction obtained.

\section{Exposure and Instrumentation}

A standard posterior midline lumbosacral approach was used to expose the spine from the upper lumbar spine (L2-3), depending on the grade of listhesis, to the sacrum. Pedicle screw fixation was used in all cases with bicortical purchase of screws obtained in

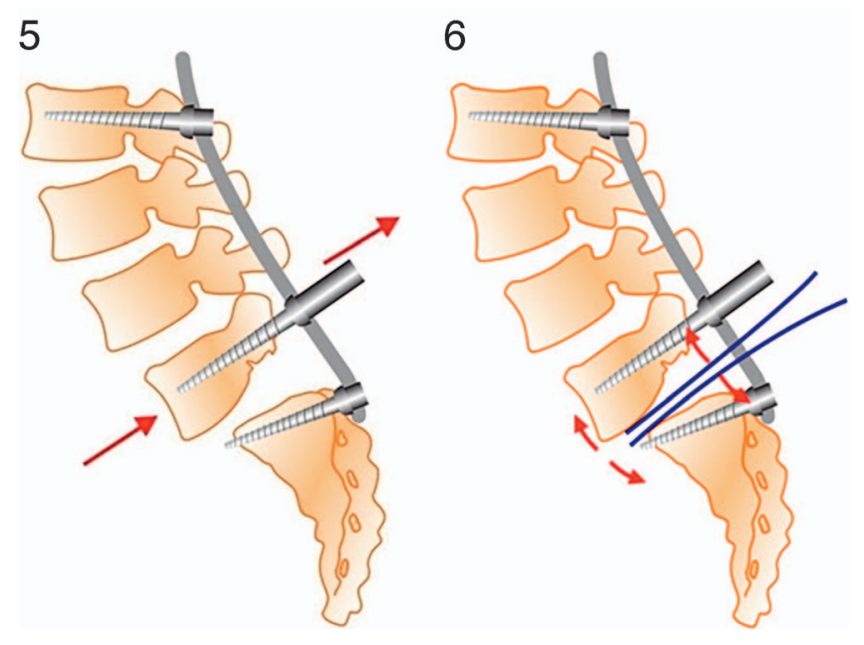

Figures $\mathbf{5}$ and 6 . Figure 5. Reduction of listhesis through L5 reduction screws or use of reducers to bring the screw to the rod. Figure 6. L5/S1 interbody space distraction to further reduce the lumbosacral kyphosis.

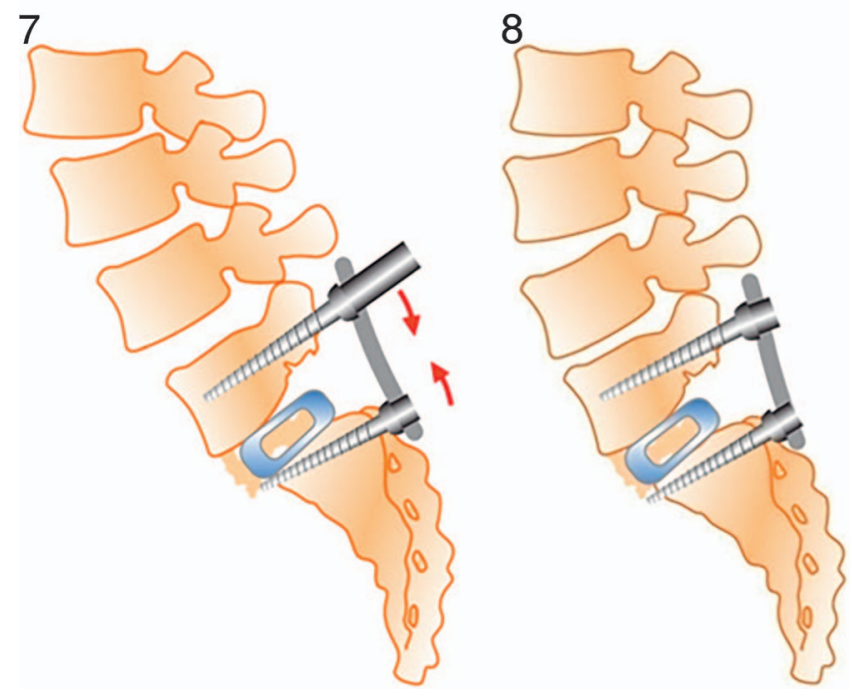

Figures 7 and 8. Removal of temporary L2-3 screws and rod followed by compression of L5/S1 over an interbody device to give final construct which shows restored sagittal balance.

the sacrum. The importance of bicortical purchase and polyaxial screws in the sacrum needs to be highlighted here as it forms an integral part of the reduction process and helps in preventing the need for sacroiliac fixations. Temporary fixation of screws at L2-3 was used to provide a long lever arm and a prebent temporary rod was placed to initiate the reduction. The rod was engaged and secured in the strong sacral screw converting the polyaxial screw into a monoaxial one and via a cantilever mechanism gradually fixed to the upper screw. Lumbosacral kyphosis was reduced by ligamentotaxis effect of gradual distraction between the screws. Polyaxial L5 screws were placed with the better visualization of the entry point at L5 obtained by this distraction maneuver. Clear visualization of L5 nerve root was possible by wide decompression.

\section{Reduction of Listhesis}

As most of the spondyloptosis cases are dysplastic with a dome-shaped sacrum, an osteotome was used to excise the dome. Bilateral lumbosacral discectomy was then performed. With compete control of the L5 nerve root (already freed from correction of lumbosacral kyphosis and posterior decompression), gentle reduction of L5 screw was performed. The reduction process would be done gradually over around half an hour. Initially, reduction screws were used; however, presently "persuaders" or tower reducers are used to gradually reduce the screw to the rod. The temporary rod on one side was replaced with the short permanent rod to bring the 


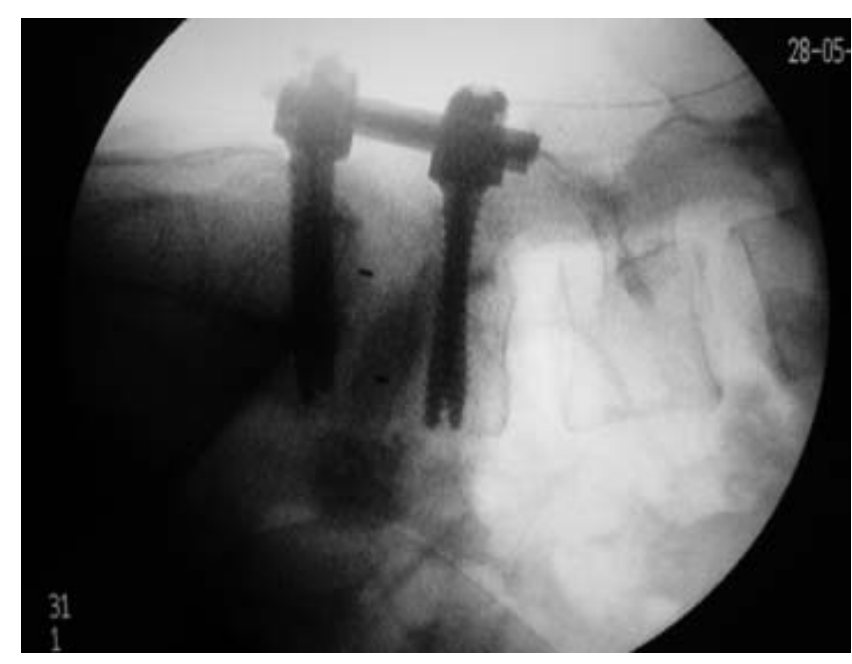

Figure 9. Image shows final construct with good reduction (spondyloptosis to grade I) and interbody fusion.

L5 body posterior with reduction of the listhesis. The exchange of rods was done one at a time to hold the reduction in position. Intraoperative images were taken at every step of reduction.

In some of our earlier cases, we performed posterolateral fusion, extended the fixation to L4, and used the Chopin plate system at the sacrum. In our later cases (year 2000 onward), an interbody device was used to maintain reduction and kyphosis correction. To this end, interbody space was distracted and an interbody device filled with local autologous cancellous bone graft was inserted. Harms cages were used for earlier cases and polyether ether ketone (PEEK) cages were used for more recent cases. The key steps of the technique include the correction of lumbosacral kyphosis with the distraction maneuver and gradual reduction of the deformity, which was followed by maintenance of reduction with posterolateral or interbody fusion, all performed in a single operation using a posterior approach.

Once the interbody reconstruction was complete, the L5-S1 construct was compressed using a contoured rod on both the sides to give the final reduction construct. None of the patients needed an additional anterior procedure or vertebrectomy. All patients were mobilized on the first postoperative day. None of the patients were casted after surgery; however, all wore an elastic lumbosacral corset for 8-12 weeks. Patients were advised to restrict forward bending and playing contact sports during this period.

\section{RESULTS}

Based on our inclusion criteria, high-grade spondylolisthesis at L5-S1 (grade 3: 3 [11.1\%] cases, grade 4: 7 [25.9\%], grade 5: 17 [63.0\%]) were operated using this progressive reduction technique. Of the 27 patients, 24 were female $(88.9 \%)$ and 3
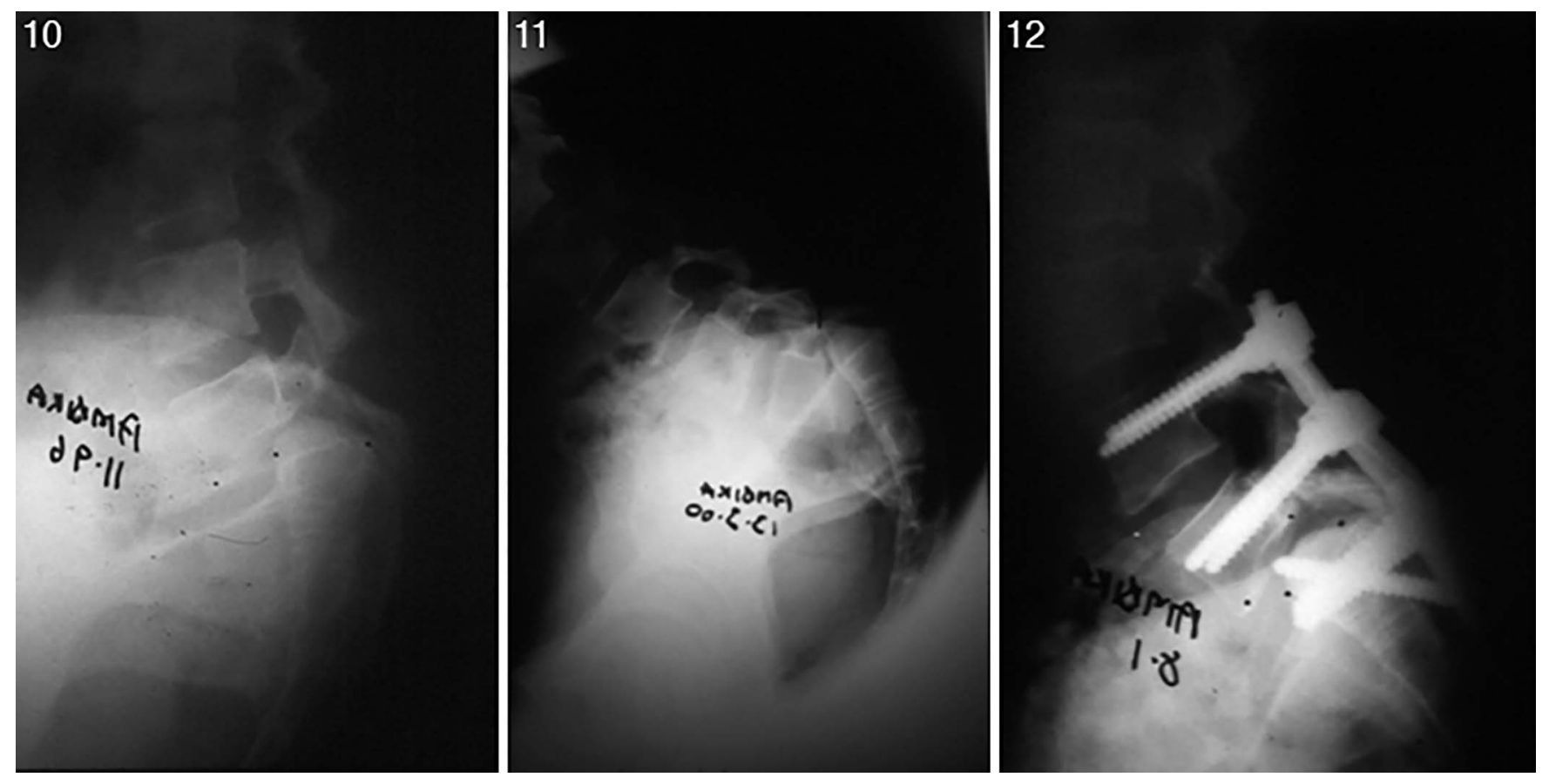

Figures 10-12. A case of 8-year-old girl with grade 4 spondylolisthesis who refused surgery, had slip progression in 4 years, and then underwent reduction and fusion. This is an example of our earliest case where fixation was extended to L4 and a Chopin plate system was used at the sacrum. 


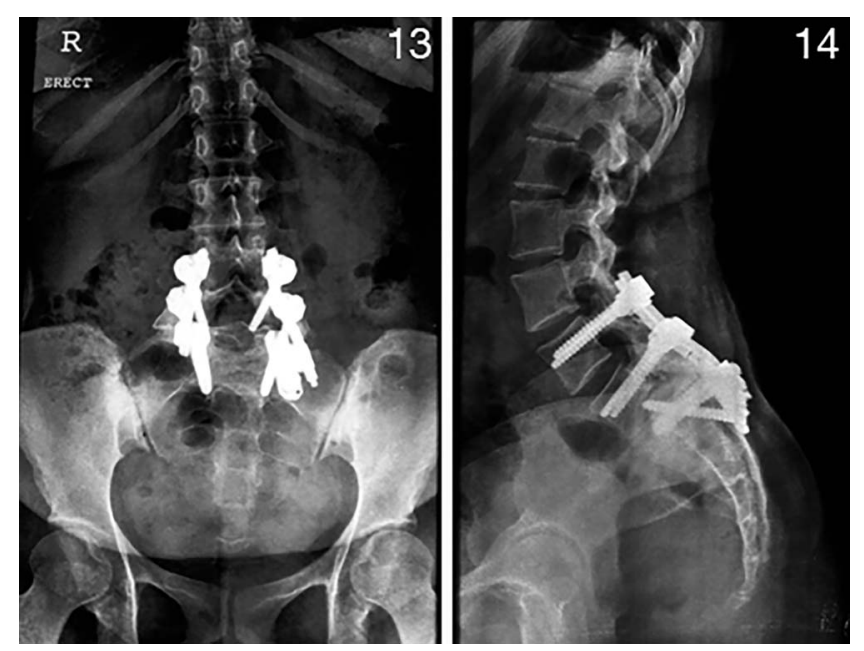

Figures 13 and 14. Eleven-year follow-up shows implants in good position, with no loss of reduction and maintenance of normal radiographic parameters.

were male, with a mean age of 13.9 years (range $7-$ 18 years).

Mean follow-up was 120 months (range 24-192 months) and all patients presented a solid fusion at the 6-month follow-up visit. The radiographic parameters measured were the mean slip percentage, slip angle, and sacral slope.

Mean slip percentage reduced from $89 \%$ to $23 \%$, with the Meyerding grade of all cases reduced to grade 2 or less. The slip angle improved from $45^{\circ}$ to $3^{\circ}$, with an improvement in sacral slope from $13^{\circ}$ to
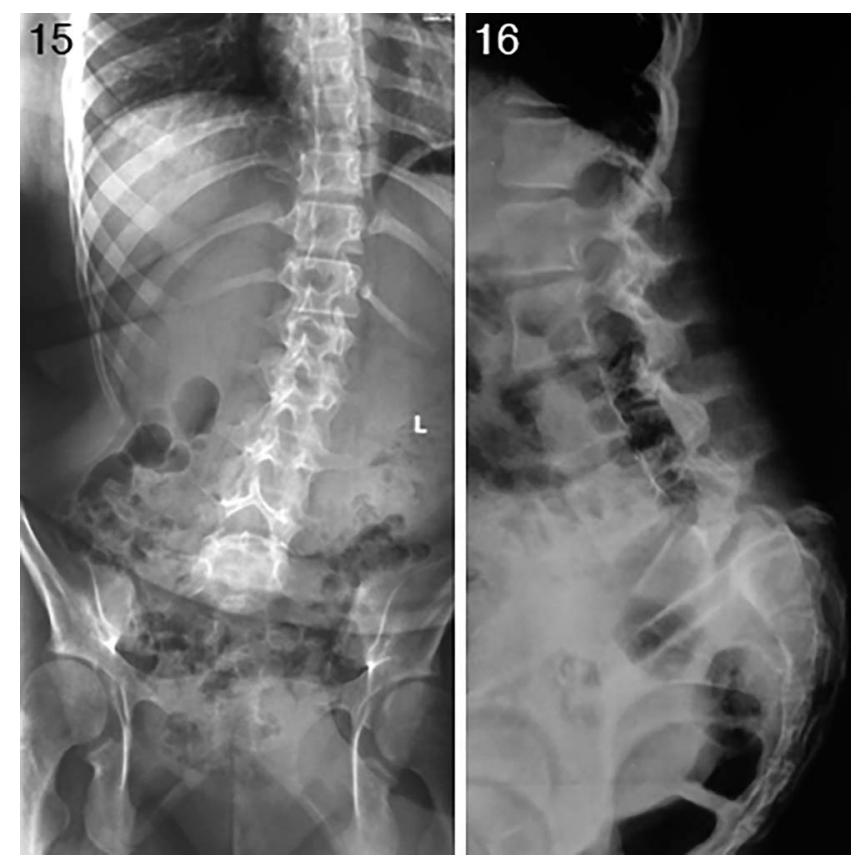

Figures 15 and 16. A case example of a 10-year-old girl with spondyloptosis who underwent the reduction technique and posterior fusion.

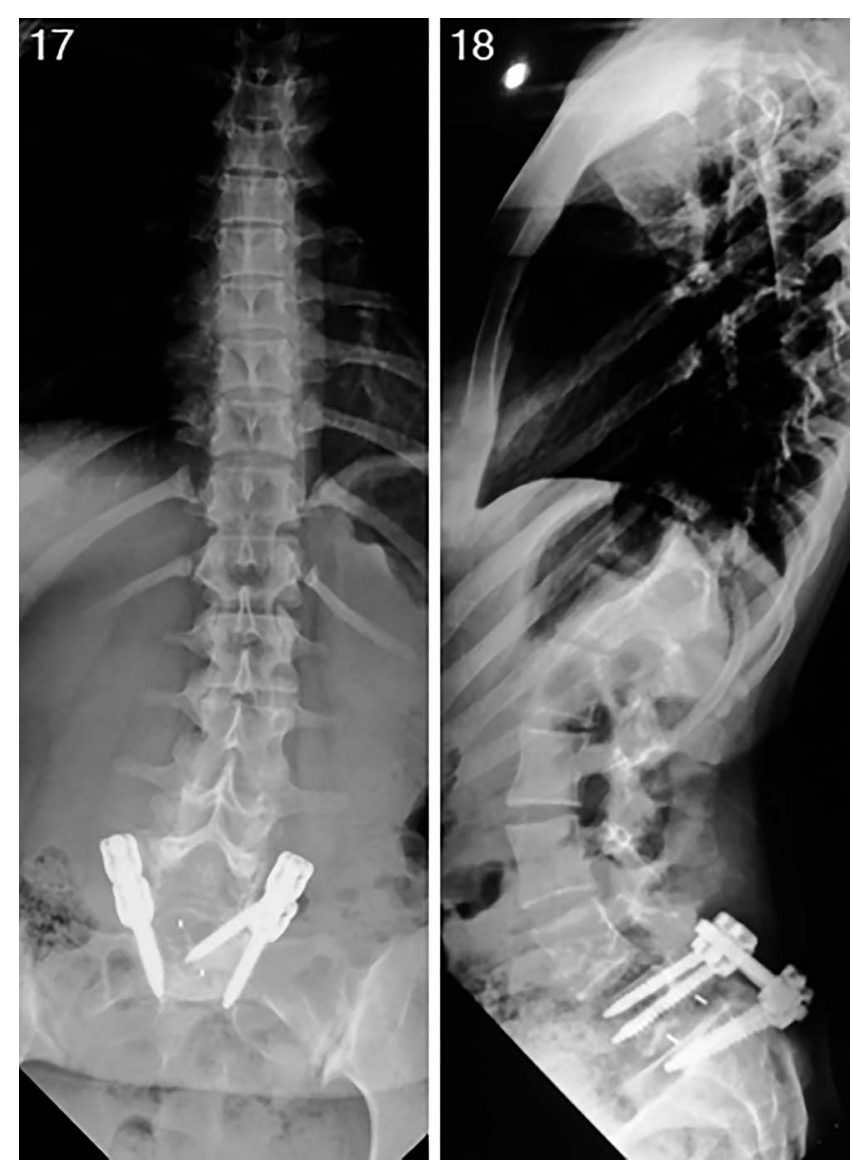

Figures 17 and 18. Two-year follow-up images showing no loss of reduction with stable pelvic parameters. Concomitant scoliosis also corrected spontaneously by surgery.

$35^{\circ}$. All the radiological parameters showed statistically significant difference $(P<.05)$ postoperatively.

Most of the literature on spondyloptosis has not stressed upon concomitant scoliosis in these patients. Four of our spondyloptosis patients had concomitant scoliosis which corrected spontaneously after the surgery and did not require further intervention.

Clinically, resolution of symptoms were noticed as early as the patients were mobilized, and straight leg raising of greater than $75^{\circ}$ in all patients was noted by 6 months after the procedure. Students returned to school and maintained excellent scholastic and athletic abilities. Four of the earlieroperated patients have married, and had children with normal delivery.

There were no intraoperative complications. One male patient had L5 screw pullout on the third postoperative day after mobilization. Fixation was revised and the implants maintained well at his 2year follow-up. Three patients (11.1\%) suffered partial drop foot that fully resolved by week 12 . All 

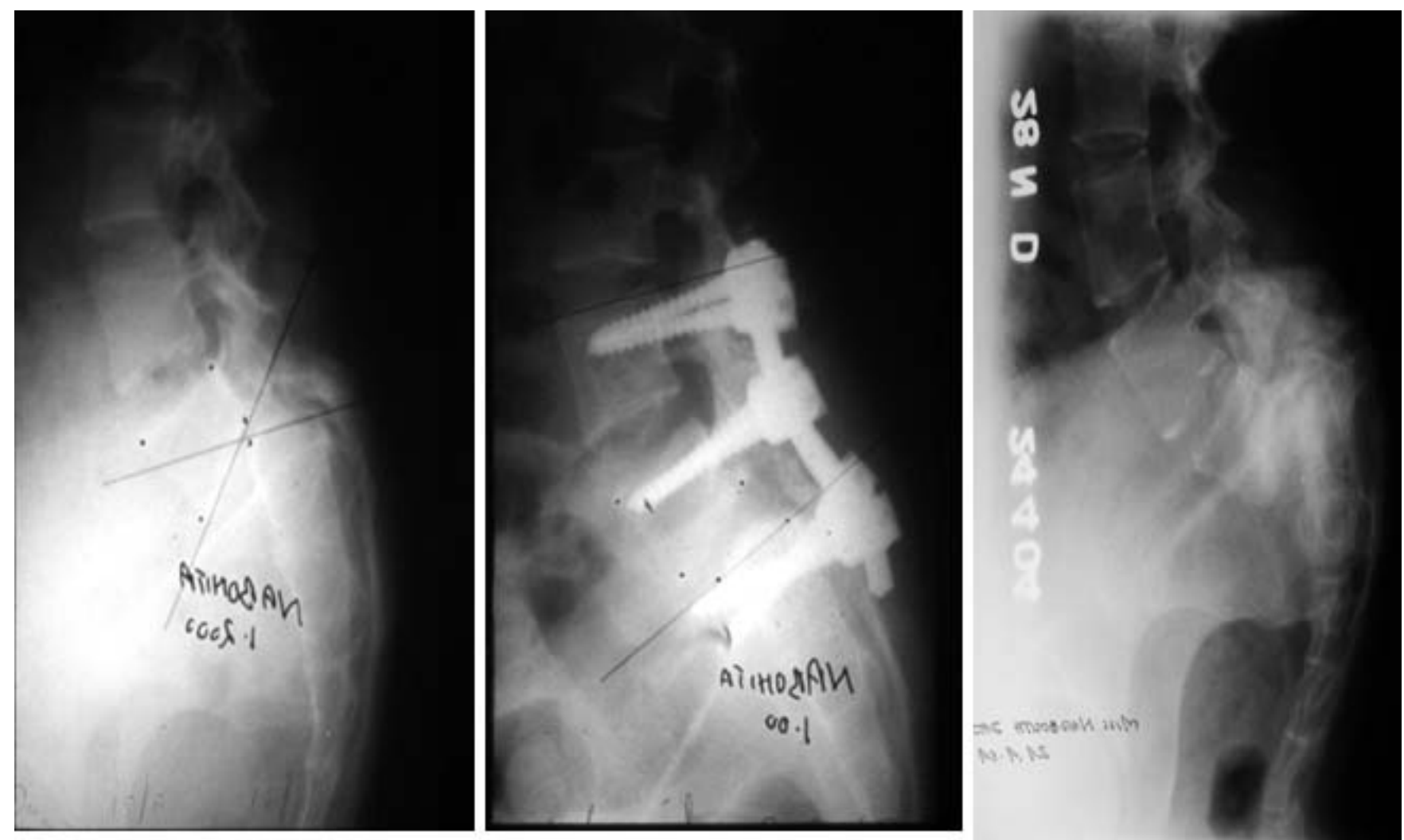

Figure 19. Images of one patient with deep infection which occurred in late postoperative period necessitating implant removal. The patient had further deformity progression at her last follow-up.

but one patient $(96.2 \%)$ had good functional outcomes and returned to their full normal activities within 3 months. One patient with poor outcome had developed a deep infection necessitating implant removal, with eventual deformity progression.

The VAS scale showed improved pain scores and a modified ODI score showed significant improvement of function postoperatively. All patients had a solid bony fusion at latest follow-up, without any pseudarthrosis, loss of reduction, or slip progression.

\section{DISCUSSION}

In the young, high-grade spondylolisthesis is etiologically attributed to the dysplasia present with secondary bony changes allowing slip progression like rounding off of the sacrum, trapezoidal L5, and verticalization of the sacrum. ${ }^{11}$ Biomechanically, kyphosis of the lumbo-sacral junction leads to compensatory mechanisms with increased lumbar lordosis and straightening of the pelvic tilt with secondary involvement of the hip and knee joints affecting the posture and gait of the patient due to anterior shift of the gravity line. ${ }^{12}$
Many surgical techniques have been suggested ranging from laminectomy to complete reduction and fusion; however, further destabilizing a spondylolisthesis by laminectomy without instrumentation will lead to progression of the slippage and an increase in pain. Posterior in-situ arthrodesis in children has also been described without laminectomy. ${ }^{13,14}$ Pseudarthrosis rates have been reported up to $40 \%$, allowing the spondylolisthesis to progress in spite of successful posterior arthrodesis. Deformity progression is very common following in-situ fusion, with increased risk with larger initial slip angles, postsurgical immobilization, and use of the Gill laminectomy technique. ${ }^{9}$ Fusion without Gill laminectomy is associated with high-grade slips, neurological deficits, and higher risk of degenerative deformity proximal to the fusion, with reports of cauda equine syndrome in few series. ${ }^{15}$

Closed reduction, plaster cast immobilization (612 weeks), followed by posterior/anterior fusion after 3-6 months has been described with satisfactory results but loss of correction is observed on long-term follow-up. Staged resection of L5 with reduction and fusion of L4 onto S1 (Gaines procedure $^{16}$ ) has shown relatively unacceptable 
complication rates. Follow-up of a series reported $25 \%$ required reoperation secondary to delayed union or instrumentation failure. ${ }^{17}$

The goals of a reduction technique are restoration of global spinal balance by correction of kyphosis at the lumbosacral junction. When achieved with the shortest possible fusion, potential adjacent disc degeneration is avoided and reduces functional restriction in these young patients. Compression in the state of lordosis has been biomechanically described to ensure better union. Intervertebral adjacent-level disc degeneration, manifested by significantly increased bending efforts, axial stiffness, and facet joint load and motion, following conventional surgical approaches, such as posterolateral/interbody fusion and decompressive laminectomy, has been reported. Some studies have reported a $50 \%$ rise in radiographically detectable adjacent level instability and disc space narrowing among posterior midline fusion versus nonfusion patients. In addition, risk of progressive deformity is higher in children and adolescents, as compared to adults, largely due to active spinal growth in these populations.

Edwards initially reported a gradual instrumented reduction technique, with a posterior-only arthrodesis, without the need for an anterior procedure and showed excellent correction of the deformity and good clinical outcome with one pseudarthrosis and one neurological deficit in his series of 25 patients. ${ }^{18}$

Harms, in his series of 112 patients, ${ }^{4}$ reported excellent results with the technique of decompression, distraction, reduction, and posterior lumbar interbody fusion in 50 patients. Distraction was obtained using hooks in the upper lumbar spine and reduction was done using long-headed pedicle screws. A more recent description ${ }^{10}$ of the technique with monosegmental fusion in 27 patients has been reported where temporary instrumentation of L4 was effective in reduction. In their opinion, as the L4/L5 segment is not primarily affected, it should be preserved whenever possible.

Shufflebarger et $\mathrm{al}^{9}$ described the results using the same techinique of wide decompression of the L5 nerve roots via Gill laminectomy, temporary distraction via sacral alar hooks and proximal lumbar hooks, lumbosacral discectomy, anterior decortications and grafting, and placement of bilateral titanium mesh cages packed with morselized autograft. Kyphosis correction is achieved by posterior compression against an anterior support and helped to restore the load-sharing ability of the anterior column.

Vialle et $\mathrm{al}^{19}$ used a same-day, staged posterioranterior approach and achieved fusion in all 40 patients with a double-plate technique. However, they had intraoperative complications like iliac vein lesion and implant complications like broken screws and 5 late infections. The authors consider the riskreward ratio to be unacceptable and indicate the approach related complications in the transperitoneal exposure. Recently, a three-staged spinal shortening procedure has been described in eight patients with good outcome, but long duration of surgery with associated risks of anterior procedure increases the morbidity associated with the surgery. ${ }^{20}$ The 2012 Scoliosis Research Society Morbidity and Mortality database report by Kasliwal et $\mathrm{al}^{21}$ reported $24 \%$ neurological complications in the form of nerve root deficits $(n=9)$, cauda equina $(n=$ $2)$, lumbar nerve palsy $(\mathrm{n}=2)$, and peroneal nerve palsy $(\mathrm{n}=2)$. A modified Bohlman technique for treatment of high-grade spondylolisthesis has been described in which they used the AxiaLif bolt rather than the fibula graft that was originally described for fusion. ${ }^{22}$

Though the usual techniques described are essentially open, a recent report by Tian et al showed posterior reduction and monosegmental fusion of L5-S1 assisted by intraoperative 3dimensional navigation as an effective technique for managing high-grade dysplastic spondylolisthesis. ${ }^{23}$ The computer-assisted navigation system provided real-time 3-dimensional images, giving surgeons the chance to dynamically select screw entry points and directions. In addition, the osteotomy procedures were performed under the navigation system to identify the position and direction of the bone drill in their series.

Our study focuses on the progressive, singlestage, posteriorly performed reduction technique with long-term follow-up, as there is an oftendebated controversy as to the most appropriate method of managing high-grade spondylolisthesis using different techniques. ${ }^{24}$ Our results compare favorably with similar techniques described before and it differs from the use of temporary pedicle screws in the upper lumbar spine rather than hooks, use of PEEK cages in our recent cases, and being less invasive, obviating the need for pelvic fixations. Though only a single case has been reported earlier, ${ }^{25}$ we report 4 spondyloptosis patients who 
had concomitant scoliosis which corrected spontaneously after the surgery.

Our series reports no permanent neurological deficits in contrast to most of the series describing reduction in high-grade spondylolisthesis. Though no neuro-monitoring was used intraoperatively in our series, we feel that the complete exposure of both L5 roots and visualization during every step of reduction, very gentle and gradual reduction maneuvers and the overall experience of the senior author are the contributing factors toward fewer complications.

\section{CONCLUSION}

The described progressive reduction technique followed by posterolateral or interbody fusion proved effective in managing high-grade spondylolisthesis in pediatric and adolescent populations, as assessed by radiographic and functional measures. A significant reduction of high-grade spondylolisthesis severity was observed, with restoration of global sagittal balance via correction of the lumbosacral kyphosis. Though surgically demanding, the technique is safe and reproducible, and the longterm outcomes are very satisfying.

\section{ACKNOWLEDGMENT}

The authors thank Dr Doron Dinstein, MD MBA (CMO, Mazor Robotics, Israel) for his contributions in the preparation of the manuscript.

\section{REFERENCES}

1. Ralston S, Weir M. Suspecting lumbar spondylolysis in adolescent low back pain. Clin Pediatr. 1998;37(5):287-293.

2. Molinari RW, Bridwell KH, Lenke LG, et al. Complications in the surgical treatment of pediatric high-grade, isthmic dysplastic spondylolisthesis. A comparison of three surgical approaches. Spine (Phila Pa 1976). 1999;24(16):1701-1711.

3. Grzegorzewski A, Kumar SJ. In situ posterolateral spine arthrodesis for grades III, IV, and V spondylolisthesis in children and adolescents. J Pediatr Orthop. 2000;20(4):506-511. https://doi.org/10.1097/01241398-200007000-00016.

4. Harms J, Jeszensky D, Stoltze D, et al. True spondylolisthesis reduction and monosegmental fusion in spondylolisthesis. In: Bridwell $\mathrm{KH}$, DeWald RL, eds. The Textbook of Spinal Surgery. 2nd ed. Philadelphia, PA: Lippincott-Raven Publishers; 1997;1337-1347.

5. Dewald RL, Taddonio RF, Neuwirth MG. Severe lumbosacral spondylolisthesis in adolescents and children. $J$ Bone Joint Surg Am. 1981;63(4):619-626.

6. Boos N, Marchesi D, Zuber K, et al. Treatment of severe spondylolisthesis by reduction and pedicular fixation. A 4-6-year follow-up study. Spine (Phila Pa 1976). 1993;18(12):1655-1661.

7. Bradford DS, Boachie-Adjei O. Treatment of severe spondylolisthesis by anterior and posterior reduction and stabilization. A long-term follow-up study. J Bone Joint Surg Am. 1990;72(7):1060-1066.

8. Petraco DM, Spivak JM, Cappadona JG, et al. An anatomic evaluation of L5 nerve stretch in spondylolisthesis reduction. Spine (Phila Pa 1976). 1996;21(10):1133-1138.

9. Shufflebarger HL, Geck MJ. High-grade isthmic dysplastic spondylolisthesis: monosegmental surgical treatment. Spine (Phila Pa 1976). 2005;30(10):S42-S48.

10. Ruf M, Koch H, Melcher RP, Harms J. Anatomic reduction and monosegmental fusion in high-grade developmental spondylolisthesis. Spine (Phila Pa 1976). 2006;31(3):269-274. https://doi.org/10.1097/01.brs.0000197204.91891.eb.

11. Marchetti PG, Bartolozzi PB. Classification of spondylolisthesis as a guideline for treatment. In: Bridwell $\mathrm{KH}$, DeWald RL, eds. The Textbook of Spinal Surgery. 2nd ed. Philadelphia, PA: Lippincott-Raven Publishers; 1997:1211-1254.

12. Boachie-Adjei O, Do T, Rawlins BA. Partial lumbosacral kyphosis reduction, decompression, and posterior lumbosacral transfixation in high-grade isthmic spondylolisthesis: Clinical and radiographic results in six patients. Spine (Phila Pa 1976). 2002;27(6):E161-E168.

13. Poussa M, Schlenzka D, Seitsalo S, et al. Surgical treatment of severe isthmic spondylolisthesis in adolescents. Reduction or fusion in situ. Spine (Phila Pa 1976). 1993;18(7):894-901.

14. Seitsalo S, Osterman K, Hyvarinen H, et al. Severe spondylolisthesis in children and adolescents. A long-term review of fusion in situ. J Bone Joint Surg Br. 1990;72(2):259-265

15. Maurice HD, Morley TR. Cauda equina lesions following fusion in situ and decompressive laminectomy for severe spondylolisthesis. Four case reports. Spine (Phila Pa 1976). 1989;14(2):214-216.

16. Gaines RW, Nichols WK. Treatment of spondyloptosis by two stage L5 vertebrectomy and reduction of L4 onto S1. Spine (Phila Pa 1976). 1985;10(7):680-686.

17. Lehmer SM, Steffee AD, Gaines RW Jr. Treatment of L5-S1 spondyloptosis by staged L5 resection with reduction and fusion of L4 onto S1 (Gaines procedure). Spine (Phila Pa 1976). 1994;19(17):1916-1925.

18. Edwards CC, Bradford DS. Instrumented reduction of spondylolisthesis. Spine (Phila Pa 1976). 1994;19(13):1535-1537.

19. Vialle R, Charosky S, Padovani J-P, Rigault P, Glorion C. Surgical treatment of high-grade lumbosacral spondylolisthesis in childhood, adolescent and young adult by the "double-plate" technique: a past experience. Eur Spine J. 2006;15(8):1210-1218.

20. Mehdian SH, Arun R. A new three-stage spinal shortening procedure for reduction of severe adolescent isthmic spondylolisthesis. Spine (Phila Pa 1976). 2011;36(11):E705-E711.

21. Kasliwal MK, Smith JS, Shaffrey CI, et al. Short-term complications associated with surgery for high-grade spondylolisthesis in adults and pediatric patients: a report from the Scoliosis Research Society Morbidity and Mortality Database. Neurosurgery. 2012;71(1):109-116

22. Hire JM, Jacobs JM, Bundy JV, DeVine JG. A modified Bohlman technique using a novel implant for 
treatment of high-grade spondylolisthesis. J Neurosurg Spine. 2015;22(1):80-83. https://doi.org/10.3171/2014.10.spine14138.

23. Tian $\mathrm{W}, \mathrm{Xu} \mathrm{Y}-\mathrm{F}, \mathrm{Yuan} \mathrm{Q}$, et al. Posterior reduction and monosegmental fusion with intraoperative three-dimensional navigation system in the treatment of high-grade developmental spondylolisthesis. Chin Med J. 2015;128(7):865. https://doi.org/10.4103/0366-6999.154278.

24. Passias P, Poorman C, Yang S, et al. Surgical treatment strategies for high-grade spondylolisthesis: a systematic review. Int J Spine Surg. 2015;9:1-21. https://doi.org/10.14444/2050.

25. Srivastava A, Bayley E, Boszczyk BM. The management of high-grade spondylolisthesis and co-existent late-onset idiopathic scoliosis. Eur Spine J. 2016;25(10):3027-3031. https://doi.org/10.1007/s00586-014-3519-0.

Disclosures and COI: The authors received no funding for this study and report no conflicts of interest. The Institutional Review Board of the
Apollo Hospital Education and Research Foundation approved this study.

Corresponding Author: Pramod K Sudarshan, MS Ortho, Spine Fellow, Apollo Hospitals, no. 21, Greams Lane, Off Greams Road, Chennai, India 600006. Phone: +91-8526616440; Fax: 91-4428294429; Email: drkspramod@gmail.com.

Published 15 August 2018

This manuscript is generously published free of charge by ISASS, the International Society for the Advancement of Spine Surgery. Copyright (c) 2018 ISASS. To see more or order reprints or permissions, see http://ijssurgery.com. 